\title{
Is there any Association between Postmenopausal Osteoporosis and Sclerostin Gene Single Nucleotide Polymorphisms in Turkish Women?
}

\author{
Derya Deveci*1 $^{\text {, Zehra Sema Ozkan }}{ }^{2}$, Hüseyin Yuce ${ }^{3}$ \\ ${ }^{1}$ Department of Medical Biology and Genetics, Firat University School of Health Services, Turkey \\ ${ }^{2}$ Department of Obsterics and Gynecology, Kırıkkale University School of Medicine, Turkey \\ ${ }^{3}$ Department of Medical Biology and Genetics, Duzce University School of Medicine, Turkey
}

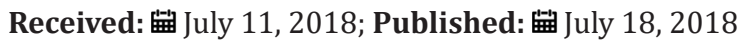

*Corresponding author: Derya Deveci, Firat Universitesi Saglık Hizmetleri Meslek Yüksekokulu, Elazig, Turkey

\section{Abstract}

Objectives: Evaluation of the probable association between bone mineral density (BMD) and SOST gene single nucleotide polymorphisms (SNPs) in postmenopausal Turkish women.

Methods: This prospective, case- control study was carried out with 204 postmenopausal Turkish women. The population was divided into 2 groups with respect to their lumbar spine T score as follows: 126 osteoporotic women with T score lower than -2.5 SD (OP group) and 78 nonosteoporotic women with T score higher than -1 SD (NOP group). Genotyping of 4 SNPs was performed using polymerase chain reaction-restriction fragment length polymorphism.

Results: There was no considerable difference between groups for parameters of age, menopausal period, weight and height. Interestingly we observed 100\% homozygote wild GG genotype for rs $17885799 \mathrm{G}>\mathrm{A}$ polymorphism and 100\% homozygous mutant AA genotype for rs851054 G>A polymorphism among whole study population. The frequency of homozygote mutant TT geneotype of rs865429 C > T polymorphism in NOP and OP groups were $78.2 \%$ and $73.8 \%$ respectively. The frequency of homozygote wild GG genotype of rs $17886183 \mathrm{G}>\mathrm{A}$ polymorphism in NOP and OP groups were $96.2 \%$ and $94.4 \%$ respectively. There was no considerable difference between groups for frequencies of all genotypes and alleles of these 4 SNPs. rs865429 C>T polymorphism showed influence on only femoral neck BMD (OR=0.7, 95\% CI: $0.866-1.846$, $p=0.000)$. And only height showed influence on femoral neck and lumbar spine BMD.

Conclusion: The association between femoral neck BMD and SOST rs865429 C>T polymorphism may open new insights on pharmacogenetic studies of osteoporosis.

Keywords: Postmenopausal Osteoporosis; Sost Gene; Polymorphism; Bone Mineral Density

Abbeviations: BMD: Bone Mineral Density; SNPS: Single Nucleotide Polymorphisms; BMI: Body Mass Index; NOP: Non-Osteoporotic; DEXA: Dual Energy X-Ray Absorptiometry; PCR-RFLP: Performed Using Polymerase Chain Reaction-Restriction Fragment Length Polymorphism; MAF: Minor Allele Frequency; SPSS: Statistical Package for Social Sciences,

\section{Introduction}

Osteoporosis is a multifactorial skeletal disorder described by reduced bone mineral density (BMD) with impaired bone microarchitecture, and increased fracture risk [1]. BMD derives the most crucial and best standard method for diagnosis [2]. Multiple risk factors influence BMD and genetic base plays a substantial mission in BMD variation [3]. It was shown by twin and family studies that genetic base constitutes about $50 \%$ to $85 \%$ of BMD [4-5]. The gene that encodes sclerostin or SOST, is mutated in the disease sclerosteosis, which is typically presented with increased BMD throughout life [6]. SOST is essentially expressed by osteocytes and SOST has been reported as one of the candidate genes for BMD and osteoporotic fractures by some researchers [7-8]. Especially transcriptional start site polymorphisms of SOST were reported as in association with BMD [9]. However, the other researchers failed to find relation between SOST gene and BMD in either premenopausal or postmenopausal women [10-11]. To date, most investigations searching the association between SOST polymorphisms and BMD variation have been done on European and Asian populations [1213]. In this study we intended to evaluate the association between BMD and SOST gene single nucleotide polymorphisms (SNPs) in postmenopausal Turkish women. 


\section{Materials and methods}

This prospective, case-control study was carried out with 204 postmenopausal Turkish women applied to Firat University Hospital, Department of Nuclear Medicine between May 2008 and December 2009 after approval of local ethics committee (with number of 06-13). The mean age, height, weight and body mass index (BMI) of the study population were $55.1 \pm 5.5$ years, $155.8 \pm 5.8 \mathrm{~cm}, 77.2 \pm 10.5 \mathrm{~kg}$ and $30.8 \pm 4.5 \mathrm{~kg} / \mathrm{m} 2$ respectively. The population was divided into 2 groups with respect to their lumbar spine T score of BMD. The osteoporotic (OP) group was consisted of 126 postmenopausal Turkish women with T score smaller than $-2.5 \mathrm{SD}$ and the non-osteoporotic (NOP) group was consisted of 78 postmenopausal Turkish women with T score bigger than -1 SD. A regardful anamnesis and physical examination was performed for all participants. Postmenopausal period, smoking, and daily oral calcium input were determined by questionnaires filled at baseline. Fasting blood glucose, hepatic and renal functions were tested. Women who had undergone ovarian surgery, who had liver or kidney disease, diabetes mellitus, other endocrine diseases or using any drug known to affect bone metabolism (such as bisphosphonates, calcitonin, glucocorticoids, antiepileptics, thyroxin, or hormone therapy) for more than 3 months were excluded from this study. Informed signed consent was taken from all participants during blood sampling.

Table 1: Primer sequences for PCR.

\section{BMD Assessment}

BMD $\left(\mathrm{gm} / \mathrm{cm}^{2}\right)$ at the lumbar spine (L1-L4) and femoral neck was measured by dual energy X-ray absorptiometry (DEXA) using DPX-L machines (Lunar Corp., Madison, WI, USA). All DEXA scans were performed by the same trained staff. The coefficient of variability values of DEXA measurements of the lumbar spine and femoral neck were 1.25 and $2.18 \%$, respectively.

\section{Genotyping and SNP Selection}

Genomic DNA was extracted from the peripheral blood using the Wizard Genomic DNA Extraction Kit (Promega,USA), with respect to manufacturer's guidelines. Genotyping for the all SNPs was performed using polymerase chain reaction-restriction fragment length polymorphism (PCR-RFLP). We designed new primers for detection of 4 SNPs of SOST gene [rs17885799($22 \mathrm{G}>\mathrm{A}) ; \quad \operatorname{rs} 17886183\left({ }^{*} 1004 \mathrm{G}>\mathrm{A}\right) ; \quad \operatorname{Rs} 851054(4534 \quad \mathrm{G}>\mathrm{A})$ and rs865429(220+675 C>T)]. These SNPs were designated according to following criteria: minor allele frequency (MAF) $>5 \%$ in Caucasians, polymorphisms formerly related with BMD in candidate gene association studies and not previously studied polymorphisms [14-16]. The primer sequences of 4 SNPs were presented on Table 1. The restriction enzymes and length of the restriction fragments were presented on Table 2.

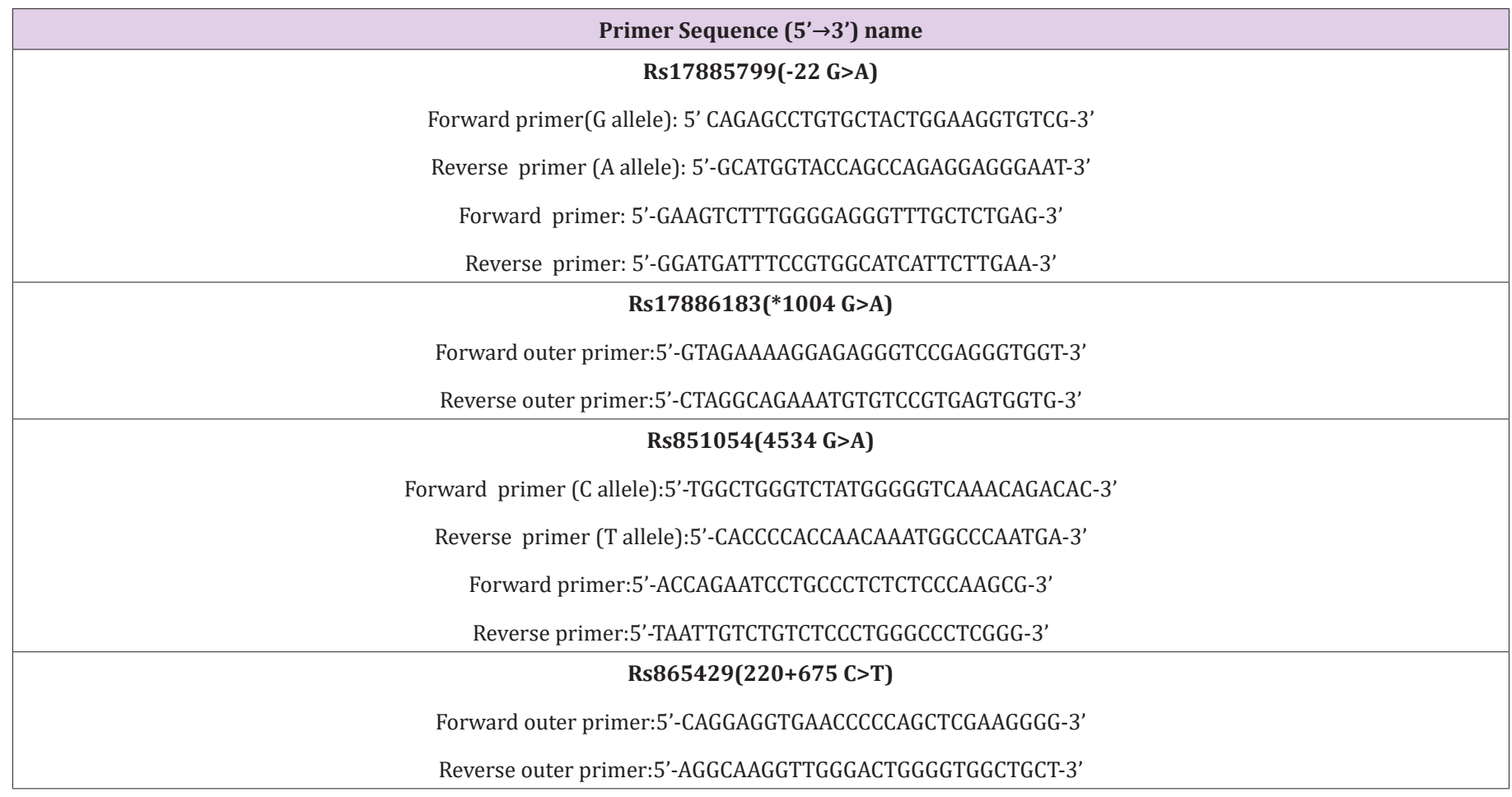

Table 2: Restriction enzymes and length of the restriction fragments.

\begin{tabular}{|c|c|c|c|c|}
\hline $\begin{array}{c}\text { SOST gene } \\
\text { (Rs number) }\end{array}$ & Polymorphism & Restriction enzyme & Cut temperature & Amplification length \\
\hline Rs 865429 & $220+675 \mathrm{C}>\mathrm{T}$ & NcoI & $37^{\circ} \mathrm{C}$ & $365 \mathrm{bp}$. \\
\hline Rs17886183 & $* 1004 \mathrm{G}>\mathrm{A}$ & Hsp92I(NlaIII) & $37^{\circ} \mathrm{C}$ & $247 \mathrm{bp}$. \\
\hline
\end{tabular}




\section{Statistical Analysis}

All data were transferred to digital media by using SPSS (Statistical Package for Social Sciences, USA) 16.0 version. The continuous variables were presented as mean \pm SD (standard deviation) and qualitative variables were presented as number and percent. The comparison of continuous variables between groups were done with Student's t-test or Mann-Whitney U-test according to normality of data. The categorical variables were compared with $\chi^{2}$ test or Fisher's exact test where applicable. Analysis of variance (ANOVA) was performed to determine the lumbar spine and femoral neck BMD values of each SNP genotype. Hardy-Weinberg equilibrium was tested for each SNP using the standard $\chi^{2}$ test.

\section{Association Analysis}

Subjects were grouped on the basis of genotype. We grouped subjects by allele copy number $(0-2$, corresponding to noncarriers, heterozygous carriers, and homozygous carriers, respectively) for each allele or haplotype. "Allele dose" was defined as the number of copies of a certain allele in the genotype. In case of a consistent trend reflected as an allele-dose effect, we performed a linear regression analysis to quantify the association after adjusting for age, menopausal period and BMI. In all analysis, a p value smaller than 0.05 was considered statistically significant.

\section{Results}

The comparison of demographic characteristics of 2 groups was presented on Table 3. There was no significant difference between groups for parameters of age, menopausal period, weight, height and BMI. Lumbar spine and femoral neck BMD values were considerably low in OP group.Genotype and allele frequencies of rs17885799 G>A and rs851054 G>A polymorphisms were presented on Table 4 . We observed 100\% homozygote wild GG genotype and $100 \%$ wild G allele among whole study population for rs17885799 G>A polymorphism. Otherwise we observed $100 \%$ homozygote mutant AA genotype and $100 \%$ mutant A allele among whole study population for rs851054 G>A polymorphism. These 2 SNPs did not show similarity for Hardy-Weinberg equilibrium. Genotype and allele frequencies of rs865429 C>T and rs17886183 $\mathrm{G}>\mathrm{A}$ polymorphisms were presented on Table 5 .

Table 3: Demographic characteristics of study population.

\begin{tabular}{|c|c|c|c|}
\hline Parameter & $\begin{array}{c}\text { NOP } \\
(\mathbf{N = 7 8 )}\end{array}$ & $\begin{array}{c}\text { OP } \\
(\mathbf{N = 1 2 6 )}\end{array}$ & P value \\
\hline Age (years) & $54.6 \pm 6.3$ & $55.3 \pm 6.2$ & 0.86 \\
\hline Menopausal period (years) & $5.1 \pm 1.7$ & $5.4 \pm 1.8$ & 0.12 \\
\hline Weight $(\mathrm{kg})$ & $77.7 \pm 11.2$ & $77.9 \pm 12.7$ & 0.55 \\
\hline Height $(\mathrm{cm})$ & $156.7 \pm 5.7$ & $155.9 \pm 6.1$ & 0.23 \\
\hline BMI $\left(\mathrm{kg} / \mathrm{m}^{2}\right)$ & $31.7 \pm 4.6$ & $30.3 \pm 4.7$ & 0.67 \\
\hline Lumbar $\left(\mathrm{L}_{1-4}\right)$ spine BMD $\left(\mathrm{g} / \mathrm{cm}^{2}\right)$ & $1.147 \pm 0.249$ & $0.882 \pm 0.102$ & 0.000 \\
\hline Femoral neck BMD $(\mathrm{g} / \mathrm{cm} 2)$ & $1.070 \pm 0.150$ & $0.880 \pm 0.110$ & 0.000 \\
\hline
\end{tabular}

Note: Values are presented as mean $\pm \mathrm{SD}$. NOP=Non-Osteoporotic; $\mathrm{OP}=$ osteoporotic; $\mathrm{BMI}=$ body mass index; $\mathrm{BMD}=$ bone mineral density

Table 4: Genotype and allele frequencies of rs17885799 G>A and rs851054 G>A polymorphisms.

\begin{tabular}{|c|c|c|c|}
\hline & $\begin{array}{c}\text { NOP } \\
(\mathrm{N}=78)\end{array}$ & $\begin{array}{c}\text { OP } \\
(\mathrm{N}=126)\end{array}$ & $P$ value \\
\hline $\begin{array}{c}\text { Rs17885799 G>A genotypes n (\%) } \\
\text {-GG (wild) } \\
\text {-GA (mutant) } \\
\text {-AA (mutant) }\end{array}$ & $\begin{array}{c}78(100) \\
- \\
-\end{array}$ & $\begin{array}{c}126(100) \\
- \\
-\end{array}$ & ND \\
\hline $\begin{array}{l}\text { Alleles n(\%) } \\
\text {-G (wild) } \\
\text {-A (mutant) }\end{array}$ & $\begin{array}{c}156(100) \\
-\end{array}$ & $\begin{array}{c}252(100) \\
-\end{array}$ & ND \\
\hline $\begin{array}{c}\text { Rs851054 G>A genotypes n(\%) } \\
\text {-GG (wild) } \\
\text {-GA (mutant) } \\
\text {-AA (mutant) }\end{array}$ & $\begin{array}{c}- \\
- \\
78(100)\end{array}$ & $\begin{array}{c}- \\
- \\
126(100)\end{array}$ & ND \\
\hline $\begin{array}{l}\text { Alleles n(\%) } \\
\text {-G (wild) } \\
\text {-A (mutant) }\end{array}$ & $\begin{array}{c}- \\
156(100)\end{array}$ & $\begin{array}{c}- \\
252(100)\end{array}$ & ND \\
\hline
\end{tabular}

Note: $\mathrm{NOP}=$ Non-Osteoporotic; $\mathrm{Op}=$ Osteoporotic; $\mathrm{Nd}=$ No Difference 
Table 5: Genotype and allele frequencies of rs865429 C>T and rs17886183 G>A polymorphisms.

\begin{tabular}{|c|c|c|c|}
\hline & $\begin{array}{c}\text { NOP } \\
(\mathrm{N}=78)\end{array}$ & $\begin{array}{c}\text { OP } \\
(\mathrm{N}=126)\end{array}$ & $P$ value \\
\hline $\begin{array}{l}\text { Rs } 865429 \text { C }>\text { T genotypes n(\%) } \\
\text {-CC (wild) } \\
\text {-CT (mutant) } \\
\text {-TT (mutant) }\end{array}$ & $\begin{array}{c}6(7.7) \\
11(4.1) \\
61(78.2)\end{array}$ & $\begin{array}{c}8(6.3) \\
25(19.8) \\
93(73.8)\end{array}$ & 0.56 \\
\hline $\begin{array}{l}\text { Alleles n(\%) } \\
\text {-C (wild) } \\
\text {-T (mutant) }\end{array}$ & $\begin{array}{c}23(15) \\
133(85)\end{array}$ & $\begin{array}{c}41(16) \\
231(84)\end{array}$ & 0.32 \\
\hline $\begin{array}{l}\text { Rs } 17886183 \text { G>A genotypes n (\%) } \\
\text {-GG (wild) } \\
\text {-GA (mutant) } \\
\text {-AA (mutant) }\end{array}$ & $\begin{array}{c}75(96.2) \\
- \\
3(3.8)\end{array}$ & $\begin{array}{c}119(94.4) \\
4(3.2) \\
3(2.4)\end{array}$ & 0.24 \\
\hline $\begin{array}{l}\text { Alleles n(\%) } \\
\text {-G (wild) } \\
\text {-A (mutant) }\end{array}$ & $\begin{array}{c}150(96) \\
6(4)\end{array}$ & $\begin{array}{c}242(96) \\
10(4)\end{array}$ & 0.51 \\
\hline
\end{tabular}

Note: $\mathrm{NOP}=$ non-osteoporotic; $\mathrm{OP}=$ osteoporotic

The frequency of homozygote mutant TT geneotype of rs865429 C>T polymorphism in NOP and OP groups were $78.2 \%$ and $73.8 \%$ respectively. The frequency of homozygote wild GG genotype of rs17886183 G>A polymorphism in NOP and OP groups were $96.2 \%$ and $94.4 \%$ respectively. While the frequency of GA heterozygote genotype in OP group was $3.2 \%$, we did not detect GA genotype in NOP group. There was no significant difference between groups for frequencies of all genotypes and alleles of these 2 SNPs. The frequency of alleles was similar with Hardy-Weinberg equilibrium (chi square=2.8; $\mathrm{p}=0.24$ for $\mathrm{rs} 17886183 \mathrm{G}>\mathrm{A}$ and chi square=1.1; $\mathrm{p}=0.56$ for $\mathrm{rs} 851054 \mathrm{G}>\mathrm{A}$ ). We compared the lumbar spine and femoral neck BMD values among genotypes of rs865429 C>T and rs17886183 G>A SNPs. There was no significant difference for BMD values of three genotypes of both polymorphisms. We also compared weight, height and BMI differences among genotypes of these two polymorphisms. There was no significant difference among genotypes for parameters of weight, height and BMI.

The association analysis performed for rs17886183 G>A and Rs865429 C>T SNPs and BMD revealed the following results. There was no association between rs17886183 G>A polymorphism and lumbar spine and femoral neck BMD. Rs865429 C>T polymorphism showed influence on only femoral neck BMD (OR=0.7, 95\% CI: 0.866-1.846, $\mathrm{p}=0.000$ ). Regression model was not applied to rs851054 G>A and rs17885799 G>A polymorphisms due to the deviation from Hardy-Weinberg equilibrium. According to linear regression model, height (OR=0.4, 95\%CI: 0.001-0.010, $\mathrm{p}=0.02$ ) and weight (OR=0.4, 95\%CI: 0.003-0.005, p=0.000) showed influence on lumbar spine BMD. And only height showed influence on femoral neck BMD (OR=0.6, 95\%CI: 0.003-0.005, p=0.000). The association analysis performed for rs17886183 G>A and Rs865429 C>T SNPs and weight and BMI revealed the following results. Rs865429
C> T polymorphism showed influence on weight (OR=0.9, 95\% CI: 35.679-39.913, $\mathrm{p}=0.000$ ) and BMI (OR=0.9, 95\% CI: 15.058-16.804, $\mathrm{p}=0.000$ ).

\section{Discussion}

In our knowledge, this is the first study demonstrating the frequency of SOST polymorphisms in postmenopausal Turkish population. The frequencies of 4 SNPs did not show significant difference between osteoporotic and non-osteoporotic postmenopausal Turkish women. We observed association between femoral neck BMD and rs865429 C>T polymorphism. Interestingly, in our population rs17885799 G>A and rs851054 G>A SNPs did not show similarity with Hardy-Weinberg equilibrium. This condition may be the result of ethnic origin and small study population.

Zhou et al. reported correlation between SOST rs851054 polymorphism and lumbar spine BMD on 639 postmenopausal osteoporotic Chinese women. Velázquez-Cruz et al. [17] Evaluated SOST gene polymorphisms on 400 postmenopausal Mexican women. They observed association between SNPs of the SOST gene and femoral neck and total hip BMD. Reppe et al. [18] investigated the epigenetic regulation of SOST expression in bone biopsies of postmenopausal Norwegian women. They declared increased CpG methylation in osteoporotic women compared to that in healthy controls. Zhang et al. [19] studied SOST gene polymorphisms on 1379 healthy Chinese women. They indicated association between lumbar spine BMD and rs2023794 and rs74252774 SNPs. He et al. searched the possible relation between BMD and SOST gene 10 SNPs (rs1234612, rs1513670, rs1634330, rs1708635, rs2023794, rs7220711, rs74252774, rs851057, rs851058, and rs865429) on 703 postmenopausal Chinese women and they did not observe an association between SOST gene SNPs and BMD. 
We observed that SOST gene rs865429 SNP has had influence on weight and BMI of Turkish women. Piters et al. evaluated SOST rs10534024 polymorphism on 783 young and 600 elder Danish men. They reported an interaction between SOST rs10534024 polymorphism and body shape, but not with BMD. This polymorphism showed influence on weight and body mass index of Danish men [20]. Genome-wide association studies have proved that SOST gene is one of the hub gene that plays role on osteoporosis pathology [21]. In a prospective cohort study, researchers observed an allele-dose effect of SOST promoter region (SRP3) polymorphism on femoral neck and lumbar spine BMD among Dutch population1. Zhou et al. defined that SOST gene polymorphisms have effect on bone metabolism via treatment modality.

They reported that SOST rs1234612 and rs851054 polymorphisms showed correlation with lumbar spine BMD before alendronate therapy. And also, they observed that SOST rs1234612 and rs865429 polymorphisms have had influence on change of femoral neck BMD after alendronate treatment. We also observed association between femoral neck BMD and rs865429 $\mathrm{C}>\mathrm{T}$ polymorphism. Liu et al. observed interaction between total hip BMD and SOST rs1513670 polymorphism on Han Chinese women. Valero et al. reported association between lumbar spine and femoral neck BMD and 5' region polymorphism of SOST gene on postmenopausal Spanish women. On the other hand, Lee et al. studied the frequency of SOST gene polymorphism on 399 Korean women and they did not find any association between SOST polymorphism and BMD [22]. Mencej-Bedrac et al. reported that they did not observe statistically significant association between BMD and SOST gene -1397_-1396insGGA polymorphism on postmenopausal Slovenian women [23].

Balemans et al. analysed 5 polymorphisms of SOST gene on 619 perimenopausal white women with either elevated or reduced BMD. They concluded that, in their study group, common allelic variations of the SOST gene did not conduce to the arrangement of BMD. Despite the relation between SOST gene polymorphisms and BMD, the definite causal SNPs and the underlying molecular mechanisms are not clearly known. Ye et al. [24]. evaluated the expression patterns of 10 SOST SNPs on human osteoblast-like cell lines. They observed allele-specific interaction with SNPs rs1230399, rs7220711, rs1107748 and rs75901553 on BMD. Zhou et al. reported that frequencies of SOST SNPs in Chinese population are comparable with those in Japanese but dissimilar from those in Europeans and Africans. In their population, lumbar spine BMD showed minor correlation with SOST rs851054 polymorphism.

In our population interestingly, rs851054 polymorphism deviated from Hardy-Weinberg equilibrium. Full population showed homozygous mutant AA genotype. This finding may arise from different ethnicity and limited population.Our study has the following limitations. Firstly, we made the comparisons between osteoporotic and non-osteoporotic women. We did not investigate the frequencies of SOST SNPs on osteosclerotic women. Secondly, we could not investigate the plasma levels of sclerostin and boneturn-over markers.

\section{Conclusion}

The association between femoral neck BMD and SOST rs865429 $\mathrm{C}>\mathrm{T}$ polymorphism may open new insights on pharmacogenetic studies of osteoporosis.

\section{Acknowledgement}

This study was financially supported by Firat University Scientific Research Foundation (FÜBAP). We thank to Dr. Tansel Balcl for her support during this study.

\section{References}

1. Uitterlinden AG, Arp PP, Paeper BW, Charmley P, Proll S, et al. (2004) Polymorphisms in the sclerosteosis/van Buchem disease gene (SOST) region are associated with bone-mineral density in elderly whites. Am J Hum Genet 75(6): 1032-1045.

2. Kanis JA, Oden A, Johnell O, Johansson H, De Laet C, et al. (2007) The use of clinical risk factors enhances the performance of BMD in the prediction of hip and osteoporotic fractures in men and women. Osteoporos Int 18(8): 1033-1046.

3. Flicker L, Hopper JL, Rodgers L, Kaymakci B, Green RM, et al. (1995) Bone density determinants in elderly women: a twin study. J Bone Miner Res 10(11): 1607-1613.

4. Ralston SH (2002) Genetic control of susceptibility to osteoporosis. J Clin Endocrinol Metab 87(6): 2460-2466.

5. Özbaş H, Tutgun Onrat S, Özdamar K (2012) Genetic and environmental factors in human osteoporosis. Mol Biol Rep 39(12): 11289-11296.

6. Brunkow ME, Gardner JC, Van Ness J, Paeper BW, Kovacevich BR, et al. (2001) Bone dysplasia sclerosteosis results from loss of the SOST gene product, a novel cystine knot-containing protein. Am J Hum Genet 68(3): 577-589.

7. Liu JM, Zhang MJ, Zhao L, Cui B, Li ZB, et al. (2010) Analysis of recently identified osteoporosis susceptibility genes in Han Chinese women. J Clin Endocrinol Metab 95(9): 112-120.

8. Yerges LM, Klei L, Cauley JA, Kathryn R, Candace MK, et al. (2009) Highdensity association study of 383 candidate genes for volumetric BMD at the femoral neck and lumbar spine among older men. J Bone Miner Res 24(12): 2039-2049.

9. Valero C, Zarrabeitia MT, Hernández JL, Pineda B, Cano A, et al. (2011) Relationship of sclerostin and secreted frizzled protein polymorphisms with bone mineraldensity: an association study with replication in postmenopausal women. Menopause18(7): 802-807.

10. Balemans W, Foernzler D, Parsons C, Ebeling M, Thompson A, et al. (2002) Lack of association between the SOST gene and bone mineral density in perimenopausal women: analysis of five polymorphisms. Bone 31(4): 515-519.

11. He J, Zhang H, Wang C, Zhang Z, Yue H, et al. (2014) Associations of serum sclerostin and polymorphisms in the SOST gene with bone mineraldensity and markers of bone metabolism in postmenopausal Chinese women. J Clin Endocrinol Metab 99(4): 665-673.

12. Styrkarsdottir U, Halldorsson BV, Gudbjartsson DF, Nelson L. S. Tang, Jung-Min Koh, et al. (2010) European bone mineral density loci are also associated with BMD in East-Asian populations. PLoS One 5: e13217.

13. Kung AW, Xiao SM, Cherny S, Li GH, Gao Y, et al. (2010) Association of JAG1 with bone mineral density and osteoporotic fractures: a genomewide association study and follow-up replication studies. Am J Hum Genet 86(2) :229-239.

14. Zhou PR,XuXJ,ZhangZL,LiaoEY,ChenDC,etal.(2015)SOSTpolymorphisms and response to alendronate treatment in postmenopausal Chinese women with osteoporosis. Pharmacogenomics16(10):1077-1088. 
15. Lhaneche L, Hald JD, Domingues A, Hannouche D, Delepine M, et al. (2016) Variations of SOST mRNA expression in human bone are associated with DNA polymorphism and DNA methylation in the SOST gene. Bone 92: 107-115.

16. Richards JB, Kavvoura FK, Rivadeneira F, Styrkársdóttir U, Estrada K, et al. (2009) Genetic Factors for Osteoporosis Consortium. Collaborative meta-analysis: associations of 150 candidate genes with osteoporosis and osteoporotic fracture. Ann Intern Med 151(8):528-537.

17. Velázquez-Cruz R, Jiménez-Ortega RF, Parra-Torres AY, Castillejos-López M, Patiño N, et al. (2014) Analysis of association of MEF2C, SOST and JAG1 genes with bone mineral density in Mexican-Mestizo postmenopausal women. BMC Musculoskelet Disord 15: 400.

18. Reppe S, Noer A, Grimholt RM, Halldórsson BV, Medina-Gomez C, et al. (2015) Methylation of bone SOST, its mRNA, and serum sclerostin levels correlate strongly with fracture risk in postmenopausal women. J Bone Miner Res 30(2): 249-256.

19. Zhang H, He JW, Wang C, Zhang Z, Yue H, et al. (2014) Associations of polymorphisms in the SOST gene and bone mineral density in postmenopausal Chinese Women. Osteoporos Int 25(12): 2797-2803.

ISSN: 2574-1241

DOI: 10.26717/BJSTR.2018.06.001429

Derya Deveci. Biomed J Sci \& Tech Res

(C) (i) This work is licensed under Creative

Submission Link: https://biomedres.us/submit-manuscript.php
20. Piters E, de Freitas F, Nielsen TL, Andersen M, Brixen K, et al. (2012) Association study of polymorphisms in the SOST gene region and parameters of bone strengthand body composition in both young and elderly men: data from the Odense Androgen Study. Calcif Tissue Int 90(1): 30-39.

21. Qin L, Liu Y, Wang Y, Guiju Wu, Jie Chen, et al. (2016) Computational Characterization of Osteoporosis Associated SNPs and Genes Identified by Genome-Wide Association Studies. PLoS One 11: e0150070.

22. Lee DO, Kim H, Ku SY, Kim SH, Kim JG (2014) Association between polymorphisms in sclerostin, dickkopfs and secreted frizzled-related protein genes and bone mineral density in postmenopausal Korean women. GynecolObstet Invest 77(3): 186-193.

23. Mencej-Bedrac S, Prezelj J, Kocjan T, Komadina R, Marc J (2009) Analysis of association of LRP5, LRP6, SOST, DKK1, and CTNNB1 genes with bone mineral density in a Slovenian population. Calcif Tissue Int 85(6): 501506.

24. Ye W, Wang Y, Mei B, Hou S1, Liu X, et al. (2018) Computational and functional characterization of four SNPs in the SOST locus associated with osteoporosis. Bone 108: 132-144.

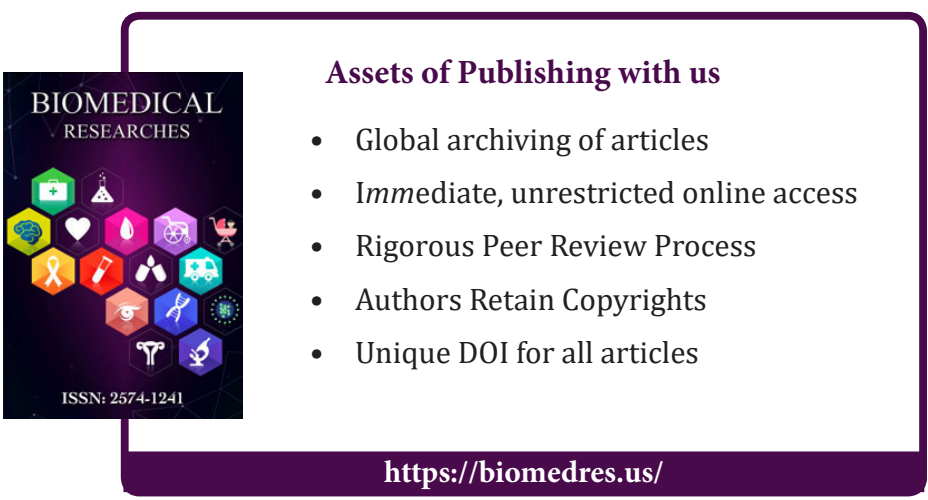

